\title{
ECOLOGICAL-EVOLUTIONARY ETHOLOGY OF THE AMPHIBIANS: CONCEPTUAL SYNTHESIS OF RESEARCH RESULTS AT REGIONAL AND EUROPEAN LEVEL
}

\section{Tudor Cozari}

State University of Tiraspol, Institute of Zoology, Chişinău, Republic of Moldova, e-mail: cozaritudor@gmail.com

\begin{abstract}
Following long-term investigations of over 50 amphibian populations in the Republic of Moldova and Italy, the ecological and evolutionary peculiarities of reproductive behavior in some species of the orders Caudata and Anura were elucidated. For the first time, at the autecological and synecological level, the evaluation of amphibian nuptial systems - parental input, reproductive success, " $\mathrm{r}$ " and " $\mathrm{K}$ " reproductive strategies and their role in the evolution of sexual selection and the realization of the reproduction potential as a fundamental mechanism for the survival of amphibian populations in various environmental conditions was emphasized.
\end{abstract}

\section{Introduction}

One of the primary ecological imperatives for humanity is the conservation and rational and sustainable use of the biological diversity of the planet. However, the existence of a considerable decline in amphibian populations caused by multiple factors and the need for the situation created, requires to effectively undertake urgent actions to investigate the reproductive systems, which assess as effective mechanisms for achieving reproductive success of species perpetuation $[1,2,4,5,7,14,17]$. The extinction of certain amphibian populations at international level is sometimes due to a negative set of demographic factors [16], although in most cases this is due to a complex action of negative anthropogenic factors and random demographic processes, or almost exclusively, only as a result of the considerable degradation of the reproductive aquatic basins $[1,2,6,12,13]$ or of the natural habitats in general [14]. Several literature data have mentioned that the problem of establishing the true causes of the ecological decline of amphibian species is difficult (and sometimes almost impossible) to solve due to the lack of long-term ecological monitoring and often the use of inappropriate or ineffective methods of estimation of the population number $[10,17]$. All mentioned eloquently demonstrates that the realization of long-term studies adequate to the batracological rigor-standards regarding the reproductive cycle and the reproduction strategies of this vulnerable group of vertebrates, have a special theoretical-scientific interest and, at the same time, they can be very useful in solving many problems related to the conservation of amphibian diversity and their rational use, both regionally and globally. The studies on estimation of the ethological and ecological-evolutionary peculiarities of amphibians in natural and anthropogenic ecosystems at local, regional and international level allowed the development of scientific-methodological support for assessing the ecological and conservation status of these vertebrates, which represent an indispensable component of the diversity of the animal world.

In the Republic of Moldova, because of the intensification of the anthropogenic impact on biological diversity, more than 240 species of animals are critically endangered, including 
9 species of amphibians, which constitutes $69 \%$ of the national batrachofauna. The ecosystems of the country are damaged, and the natural areas are not able to fulfill their function of stabilizing the ecological systems. The recovery of the situation of animal world diversity requires essential efficiency of measures to conserve biodiversity and natural habitats, rational and sustainable use of biological resources, restoration of degraded ecosystems and endangered species, identification of valuable sectors in terms of biological diversity and promotion of biodiversity activities, extension of the fund of protected natural areas. In this sense, the Network of State Protected Areas is of particular interest for the conservation of biodiversity, including amphibians. These studies are in line with the criteria of the International Union for Conservation of Nature (IUCN) and the requirements of the Convention on Biological Diversity. The natural sites of the universal natural heritage are protected natural areas whose destination is the protection and conservation of natural habitat areas, including those populated by amphibians, on which territory there are natural elements whose value is recognized as being of universal importance.

\section{Materials and methods}

The methodology of scientific research is constituted by the theoretical-scientific conceptions exposed in the works elaborated by batrachological scientists $[8,9,11,13,14,15,17]$, regarding the eco-ethological structure of the populations, nuptial systems and reproduction strategies, intra- and interpopulation mechanisms of reproductive systems, parental investment and reproductive success, ecological evolutionary peculiarities of selection „,r, and „K, , mechanisms of sexual selection, the role of acoustic communication in achieving intra- and intersexual relationships and in achieving maximum reproductive success.

The aim of the long-term investigations (over 30 years) focused on the autecological and synecological substantiation of an integrated and detailed conception of the nuptial systems and breeding strategies of amphibian species in natural and man-made ecosystems in order to establish evolutionary particularities of ecological and behavioral mechanisms of intrapopulation and interpopulation mechanisms of species perpetuation. For this purpose, over 50 populations from the Republic of Moldova and Italy were analyzed in 13 species of amphibians of the genera Triturus, Bufo, Pelobates, Bombina, Hyla and Rana from the orders Cautata and Anura.

\section{Results and discussions}

The results obtained have a fundamental theoretical significance, which is summarized by:

- At the autecological and synecological level, the nuptial systems of amphibians - parental input, reproductive success, " $r$ " and " $K$ " reproductive strategies and their role in the evolution of sexual selection and in the realization of reproductive potential as a fundamental mechanism of survival of amphibian populations in various environmental conditions;

- It has been established that amphibians are characterized by a relatively high level of ecological plasticity of reproductive strategies - as an evolutionary ecological complex and species-specific behavioral complex, which is aimed at ensuring an optimal level of sur- 
vival of local populations in various conditions of natural and anthropogenic ecosystem; - The results obtained contribute to the essential strengthening of the concept of reproductive systems and strategies in fluctuating conditions of ecological factors in natural and anthropized ecosystems;

- The intersexual mechanisms of communication of native amphibian species have been elucidated, the legities of acoustic communication has been established, which can be used to assess the problems of the emergence and evolution of perception and communication systems of individuals and to develop mathematical, ecological and ethological models of nuptial systems for this group of vertebrates;

- It has been established that amphibian calling songs are valued as important factors in sexual selection; which indicates that the phenomenon of female preference toward calling songs with a higher intensity could significantly influence the reproductive success of males within the same population.

Therefore, the results obtained, both experimentally and in natural conditions with amphibian populations of different species from the Republic of Moldova and Italy, allow us to conclude that the intensity of the calling songs of the males represent an important criterion in determining the reproductive success. The data on the mechanism of egg fertilization are fundamentally new to science and considerably expand the existing theoretical concepts regarding the process of fertilization of ecaudata amphibians - appreciated as an intrinsic external type (as previously considered). However, we have established that the fertilization of eggs is carried out in a strictly delimited aquatic space (created by the two conjugal partners through a specific positioning of the body and limbs) which ensures the complete fertilization of the eggs.

This mechanism of egg fertilization is, in fact, an intermediate fertilization mechanism (transient) between the external type (particular for fish - ancestors of amphibians) and the internal type (particular for reptiles - class of vertebrates evolved from amphibians). Thus, for the first time, we established that according to the reproductive system also, the ecaudata amphibians occupy an intermediate position between the class of fish and the class of reptiles - this being one of the fundamental evolutionary concepts of zoology regarding the origin of amphibians. For the first time, models of the nuptial systems of caudata and ecaudata amphibian species were developed. These ethological models have been developed for the following amphibian species: Hyla arborea, Rana dalmatina, Triturus cristatus, Triturus vulgaris, the green frog complex $-R$. lessonae $x$. ridibunda $\times R$. esculenta.

These complex studies carried out at regional (Republic of Moldova) and European level (five regions of Italy) with the use of high-performance contemporary methodologies (spectral analyzes of the sounds emitted by amphibians in the most diverse ecological and ethological conditions), allowed to elaborate the following theoretical concepts new for science:

- The effect of the complementarity of the structural and temporal factors in the acoustic communication of the individuals of the ecaudata amphibian species at intra- and interpopulation level and in the realization of the sexual selection;

- Mimicking the opposite sex by non-territorial males in intrasexual relationships within 
the populations - as a reproductive strategy and one of the forms of sexual selection in caudata amphibians;

- Male satellite-ism as an opportunistic form of sexual behavior in amphibians;

- The effect of the integrity of the sensory channels of chemical, optical and tactile communication in the realization of sexual selection in amphibians.

The main scientific results regarding the evolutionary, ecological and ethological peculiarities of amphibians obtained after long-term investigations in natural conditions lies in:

1. At the basis of the formation of amphibian complexes under diversified and variable ecosystem conditions are intra- and interpopulation co-adaptive mechanisms, labile in time and space, which allow amphibian populations to consistently and efficiently use the abiotic and biotic resources of habitats.

2. There is a very close correlation between the duration of the reproductive period and the specific manifestation of amphibian reproduction strategies. Thus, depending on the length of the breeding period, the caudata and ecaudata amphibians fall into two broad categories:

a) Amphibians with a short reproductive period (also called "explosive"), lasting 7-10 days;

b) Amphibians with a long reproductive period, lasting more than a month.

The main breeding strategy, used by males of short-breeding species, is not to attract females by acoustic signals and through the manifestation of territorialism, but by direct competition ("scramble competition") with other rivals, and their reproductive success depends entirely on their competitive ability.

On the contrary, the strategy of reproduction of species with a long reproductive period consists in:

a) The protection of an individual territory and the attraction of the female through chemical communication, nuptial coloration and certain demonstration postures - in caudata amphibians (genus Triturus);

b) The protection of an individual territory and the attraction of the female through the issuance of calling songs - in ecaudata amphibians (genera - Bufo, Hyla, Rana etc.).

An alternative reproductive strategy of the males of some species with a long reproductive period consists in the satellite behavior of the males, called by us the concept of satelliteism, which was first discovered and evaluated in the species Hyla arborea. Male satelliteism has emerged as an opportunistic form of sexual behavior in equatorial amphibian species and is geared toward achieving the reproductive success of non-territorial males that act as dominant male-territorial satellites.

The effect of satellite has a frequency of about $11 \%$ in breeding populations and is an important source of realization of the reproductive potential of populations of ecaudata amphibians.

1. For the first time, the principles of integrating the chemical (a), optical (b) and tactile (c) sensory communication channels into sexual selection in ecaudata amphibians were evaluated: 
a) Chemical communication is used, in fact, to ensure the effective interaction of partners during reproduction - to protect the individual territory, attracting and conquering the female, communicating about the onset of spermat ophore deposition process, stimulating the female to capture sperm laid by the male. The essence of chemical communication in caudata amphibian species consists in: 1 . Transmitting information about the physiological state of the conjugal partner (the fact that the sperm or eggs are already mature and ready for deposition and fertilization); 2 . The arousal of the conjugal partner so that he initiates the realization of certain nuptial behaviors that are directed towards the deposition of gametes and the realizations of fertilization.

b) Optical communication also plays a fairly important role, manifesting as one of the effective mechanisms for recognizing the conspecific individual, but also for achieving nuptial behavior as a complex of nuptial demonstration postures designed to ensure sexual selection at the intrapopulation level;

c) Tactile communication has a secondary and / or complementary role, meant to strengthen the effect of the two main sensory communication channels - the olfactory and optical one.

2. The effective realization of the reproductive potential in amphibian populations is determined by the nuptial system and reproductive strategies, which establish the level of reproductive success in the given environmental conditions.

3. The role of the fundamental frequency of amphibian male calling songs was assessed, based on which females have the opportunity to choose larger males so that the dimensional difference between them and males would be minimal and thus the sexual partners' cloaca overlap; thus ensuring a high level of fertilization of the eggs during reproduction.

4. The phenomenon of the manifestation of female preferences toward calling songs with certain frequency is a complex one and, therefore, in order to determine the true causes of the its manifestation and role in sexual selection, it is necessary to analyze female preference not only according to a single sound parameter, but of several parameters, take together (such as, for example, intensity and frequency, duration and frequency, etc.). By doing so, it was possible to establish the presence of a new concept of acoustic communication in amphibians - the effect of complementarity (interdependence of sound parameters) of structural and temporal factors in acoustic communication of individuals intra- and interpopulation and sexual selection.

5. The nuptial systems of local amphibian populations are strongly influenced by certain environmental factors, in particular by the spatial and temporal distribution of breeding habitats and the length of the breeding period;

6. In the evaluated amphibian populations, the manifestation of the reproduction strategies " $r$ " and "K" presents certain intra- and interpopulation features, which are determined by certain endogenous and exogenous factors. The inter- and intrapopulation variability of the " $\mathrm{r}$ " and " $\mathrm{K}$ " reproduction strategies of amphibians is evolutionary, it appeared and consolidated within the populations as an efficient mechanism of species-specific surviv- 
al.

Research to estimate the ethological and ecological-evolutionary peculiarities of amphibians in natural and anthropogenic ecosystems at local, regional and international level allowed to develop a scientific-methodological support for assessing the ecological and conservation status of these vertebrates - which represent an indispensable component of the animal world diversity.

The studies were performed within the State Program project 20.80009.7007.02.

\section{Conclusions}

In amphibian populations the manifestation of reproduction strategies " $\mathrm{r}$ " and " $\mathrm{K}$ " have certain intra- and interpopulation features, which are determined by certain endogenous and exogenous factors.

The inter- and intrapopulation variability of the " $r$ " and " $\mathrm{K}$ " reproduction strategies of amphibians is of evolutionary order, it appeared and consolidated within the populations as an efficient mechanism of species-specific survival.

An alternative reproductive strategy of the males of some amphibian species with a long reproductive period consists in the satellite behavior of the males, which was evaluated for the first time in the species Hyla arborea. Male satelliteism has emerged as an opportunistic form of sexual behavior, aimed at achieving the reproductive success of non-territorial males that act as satellites of dominant territorial male.

The effect of satelliteism has a frequency of about $11 \%$ in breeding populations and is an important source of realization of the reproductive potential of amphibian populations.

The effective realization of the reproductive potential in amphibian populations is determined by the nuptial system and reproductive strategies, which establish the level of reproductive success in the given environmental conditions.

A new principle has been established in the system of acoustic communication in amphibians - that of the complementarity effect (interdependence of sound parameters) of structural and temporal factors in the acoustic communication of individuals at intra- and interpopulation level and in sexual selection.

\section{Bibliography}

1. Cozari T. Etologie ecologică. Chişinău: Litera, 2001. 176 p.

2. Cozari T. Strategii de reproducere a amfibienilor. Particularităţile evolutive ecologice în ecosistemele naturale şi antropizate. Chişinău: Ştiinţa, 2010, 288 p.

3. Cozari T., Jalbă L. Biologia, ecologia şi comportamentul speciei Triturus cristatus în Codrii Centrali. Chişinău, 2009, 112 p.

4. Dediu I. Ecologia populațiilor. Academia Națională de Științe Ecologice. Chișinău, 2007, 178 p.

5. Dediu I. Enciclpedie de ecologie. Ch.: Î.E.P. Știința, 2010, 836 p.

6. Plop L., Toderaș I., Cozari T. Biologia, ecologia şi comportamentul speciei Triturus vulgaris în Codrii Centrali. Chişinău: Red. Șt. Ion Toderaș. - Chișinău: Academia Militară “Alexandru cel Bun", 2015. - 122 p.

7. Balletto E., Giacoma C. Stochasticx extinction probabylity for European popultions of Hyla 
arborea: an approach by VORTEX. In A.H.P. Stumpel and U. Tester (eds.), Ecology and Conservation of the European Tree Frog, Hyla arborea. Postdam, Germany. 1993, p.81-90.

8. Bannicov A.G., Darevschii I.S., Iscenco V.G., Rustamov A.K., Scerbak N.N. Opredeliteli zemnovodnîh i presîmîcaiusciesea faunî S.S.S.R. 1977, M., 415 c.

9. Dodd C.K. Jr. Monitoring amphibians in Great Smoky Mountains National Park. U.S. Geological Survey Circular 1258, Tallahassee, Florida, U.S.A. 2003. 124 p.

10. Dunson W.A., R.L. Wyman, E.S. Corbett. A Symposium of Amphibian Declines and Habitat Acidification. In: Journal of Herpetology, 1992. Nr. 26, p. 349-352.

11. Howard P.D. Sexual selection on male body size and mating behavior in American toADS, Bufo americanus. In: Anim. Behav., 1988. Vol. 36, p. 1796-1808.

12. Pavignano I., Cozari T. Structtura di popolalazione di Bufo viridis. In: Atti del 53 Congresso dell Unione Zoologica Italiana. Palermo. 1990, p. 71-76.

13. Ryan M.J. Sexual selection, sensory system and sensory exploitation. In: Futtuyma D., Oxford surxeus of evolutionary biology. Oxford Univ. Preess, Oxford. 1990. P.157-195.

14. Ryan M. J. Annuran Communication. Smithsonian Institution Press, Washington, DC. 2001, $168 \mathrm{p}$.

15. Trivers R. L. Parental investment and sexual selection. In B. Camp-bell, ed.: Sexual selection and the descent of man, 1871-1971. Aldine Publishing Co., Chicago, 1971, - p. 136-179.

16. Wells K.D. Ecology and Behavior of Amphibians. The University of Chicago Press, Chicago and London. 2007, 1148 p.

17. Wilson E. O. Sociobiologia. Trad.: Louis Ulrich. Bucuresti. Editura TREI. 2003, 507 p. 